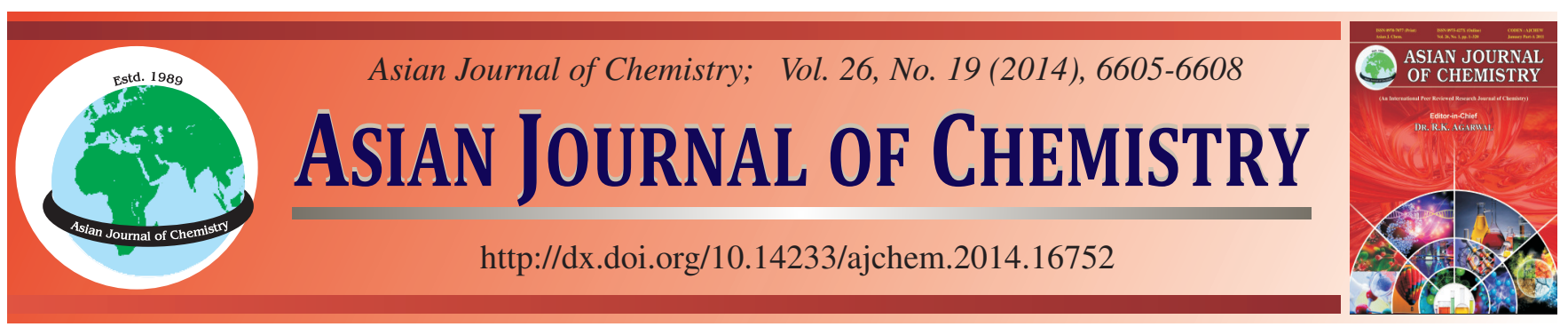

\title{
Derivatizing Condition of Trace Dicyandiamide with Dansyl Chloride and Application of Spectrum Analysis Method
}

\author{
Huidong Qiu ${ }^{1,2, *}$, Dongdi Sun ${ }^{2}$ and Todd MLSNA ${ }^{2}$
}

${ }^{1}$ Department of Chemistry and Chemical Engineering, Chong Qing University of Science and Technology, Chongqing 401331, P.R. China ${ }^{2}$ Department of Chemistry, Mississippi State University, Mississippi State, MS 39762, USA

*Corresponding author: E-mail: qhd324@163.com

Accepted: 19 March 2014;

Published online: 16 September 2014;

AJC-15971

\begin{abstract}
A dicyandiamide dansylation procedure compatible with UV spectum was presented. The method provides quickly derivatization while the ratio of dansyl chloride to dicyandiamide over a 10000-fold range, buffer $\mathrm{pH}$ of 9.5 , ambient temperature of $40{ }^{\circ} \mathrm{C}$ and reaction time of $10 \mathrm{~min}$. The method is convenient only using a simple UV spectrometers and successfully achieved method limit of quantification 30 $\mathrm{ng} / \mathrm{L}$ in water sample.
\end{abstract}

Keywords: Dansyl chloride, Dicyandiamide, Derivation, Spectrum analysis.

\section{INTRODUCTION}

Dicyandiamide is a synonymous name for the dimer of cyanamide, which itself is used broadly in industrial production of melamine or in the agricultural industry of chemical fertilizer $^{1-3}$. Joji et al. ${ }^{4}$ reported that cyanamide group, a hydrolyzate of calcium cyanamide is another fertilizer, while in the $\mathrm{pH}$ range of 8-12 it begins to form dicyandiamide. Because of heavy used of the dicyandiamide fertilizer in pasture and caused the pollution event of dicyandiamide residue in milk or dairy products ${ }^{5,6}$. Because drinking water source for animal in many pasture and dicyandiamide is stability in water. Therefore, people are need to pay attention to the dicyandiamide residues in water.

Interestingly, although a paper chromatography method ${ }^{7}$ was reported in 1956 for cyanamide and dicyandiamide. Subsequently, many of high performance liquid chromatography methods have been applied in retention analysis of food and medical industry ${ }^{8-18}$. However, some study can detected $100 \mathrm{ng} / \mathrm{mL}$ dicyandiamide by HPLC in aqueous solution ${ }^{13}$, although some method LOQ can up to $0.5 \mathrm{ng} / \mathrm{g}$ of dicyandiamide in dairy products by HPLC-DAD ${ }^{18}$ and another study also measured the $0.3 \mathrm{ng} / \mathrm{mL}$ of trace dicyandiamide in food samples by HPLC-MS-MS ${ }^{14}$. But most of them employ either sophisticated detection or tandem mass spectrometry and may be considered test cost expensive. In addition, it hasn't been reported that determination method of dicyandiamide in water. Therefore, it is necessary to develop a simple and inexpensive method for analysis of trace dicyandiamide in aqueous solution.
Trace dicyandiamide, because of low sensitivity, can not be readily analyzed directly by UV spectrophotometer. This problem can be overcome by derivatization to chromophore or fluorophore. Derivatization technology $y^{19-21}$ is generally used to change the physicochemical properties of compounds of interest for better analytic sensitivity and selectivity. Dansyl chloride $^{22-25}$ has a reactive sulfonyl chloride group, it has been used for many years fluorescent reagent to covalently tag end amino groups. Herein, the paper describes the application of dansyl chloride as a derivatization reagent for dicyandiamide and investigated derivatization conditions: such as $\mathrm{pH}$ of solution, derivatization temperature and time, etc. Furthermore, investigated the stabilization for derivatization agent and derivative.

\section{EXPERIMENTAL}

The required analytical standard of dicyandiamide and derivatization reagent of dansyl chloride (bioreagent, $\geq 99 \%$ HPLC grade) were purchased as powders from Sigma Aldrich (USA); sodium carbonate, sodium bicarbonate, extraction reagent of ethyl acetate and solvent of acetonitrile were purchased from Fisher Scientific (USA). Ultrapure water used was purified through a Milli-Q system (Millipore, USA). Dicyandiamide standard stock solution (1000 mg/L) was prepared by ultrapure water in a $100 \mathrm{~mL}$ volumetric flask and dansyl chloride stock solution $(1000 \mathrm{mg} / \mathrm{L})$ was prepared by acetonitrile in a $100 \mathrm{~mL}$ brown bottle, the stock solution were stored at $4{ }^{\circ} \mathrm{C}$ for one month. All chemicals and solvent were used as received without any further purification. 
UV spectrophotometer were carried out with a Shimadzu UV2550 (Shimadzu scientific instruments). The software used to record UV spectrum was UV Prob (Columbia, MD, USA). The solutions were placed in $0.5 \mathrm{~cm}$ path-length quartz cell for the measurement at ambient temperature $\left(25^{\circ} \mathrm{C}\right)$. Nitrogen evaporator-N-EVAPIII (Organmation Associates Inc.) for the quickly removal the ethyl acetate at water bath $\left(40{ }^{\circ} \mathrm{C}\right)$.

Derivatization reaction and experimental method: With a pipettor, $1 \mathrm{~mL}$ sample solution (or dicyandiamide standard solution) and $1 \mathrm{~mL}$ of the derivatizing agent $(1000 \mathrm{mg} / \mathrm{L})$ were accurately withdrawn and transferred to screw-cap test tube, respectively. And $1 \mathrm{~mL} \mathrm{NaHCO}-\mathrm{Na}_{2} \mathrm{CO}_{3}$ buffer solution ( $\mathrm{pH}$ 9.5) was added reaction solution. Then the test tube was stirred on magnetic stirring apparatus. And the reaction temperature at $40{ }^{\circ} \mathrm{C}$ for $10 \mathrm{~min}$.

After reaction, dried acetonitrile by nitrogen evaporator, then extracted new derivative (Fig. 1) using $3 \mathrm{~mL}$ of ethyl acetate at twice respectively and amalgamated extracted liquid into $10 \mathrm{~mL}$ test tube, subsequently dried the ethyl acetate by nitrogen evaporator at water bath $\left(40{ }^{\circ} \mathrm{C}\right)$ and dissolved the residue by $2 \mathrm{~mL}$ acetonitrile. The dicyandiamide derivative was analyzed using UV spectrophotometer of wavelength at $240 \mathrm{~nm}$ and reagent blank is used as reference solution.

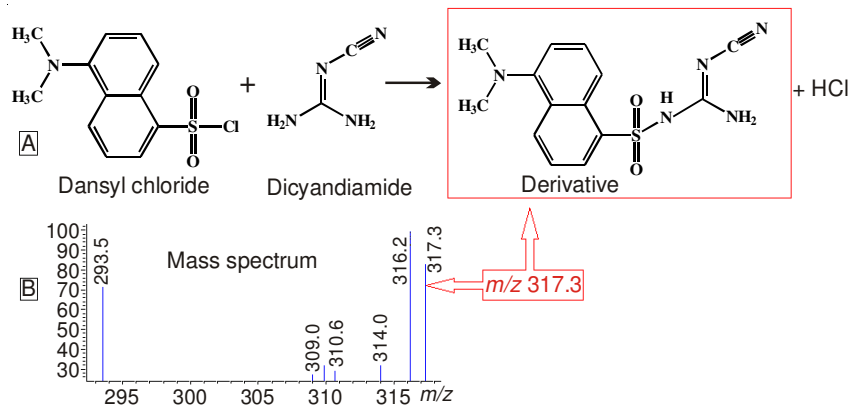

Fig. 1. (A) Dansylation reaction for dicyandiamide (B) Mass spectrum of derivative

\section{RESULTS AND DISCUSSION}

UV spectroscopy: The absorption spectra (shown in Fig. 2.) of dicyandiamide, dansyl chloride (DNS) and derivative were recorded at the same solvent of acetonitrile. Dicyandiamide (DCD) has only one absorbance at $219 \mathrm{~nm}$. Dansyl chloride has a maximum absorbance at $209 \mathrm{~nm}$ and $-\mathrm{SO}_{2}$ - group give a small shoulder at $240 \mathrm{~nm}$. New derivative (DCD-DNS) absorbance spectrum is similar compared with DNS, because of only sulphonyl group turn into sulfamide group. And the experiment shown a strong absorption at 240 $\mathrm{nm}$ consist with the theory characteristic of $-\mathrm{SO}_{2}-\mathrm{NH}$ - group. Furthermore because - $\mathrm{SO}_{2}-\mathrm{NH}$ - group unsaturated enhancement and conjugative effect enhancement, $\pi \rightarrow \pi^{*}$ electronic transition $\Delta \mathrm{E}$ decrease, electronic transition probability is increase, which enhances the absorbance intensity and improve the analysis sensitivity. The $240 \mathrm{~nm}$ was selected as analysis wavelength in the experiment. In addition, the mass spectrum of new derivative molecular ion $m / z=317.3$ was also shown in Fig. 1.

Optimization of dansylation condition: Previously reported $^{25-30}$ conditions for dansylation differ from group to

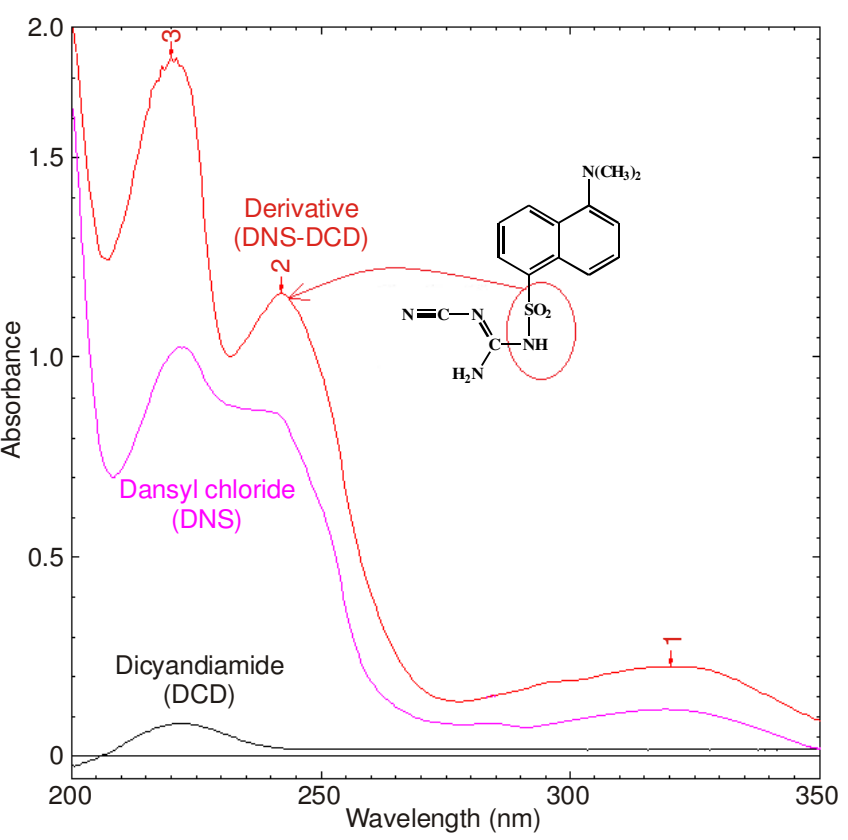

Fig. 2. UV spectra at the same solvent of acetonitrile

group, but have some influencing factor in common. The key factors affecting derivatization are usually involved in dynamic interaction, therefore the optimization of dansylation procedure was carried out by investigating the influences concentration ratio of dansyl chloride to dicyandiamide, derivatization time and temperature and buffer $\mathrm{pH}$. After reviewed the related literatures, the suggested experiments and the evolution of membership value were shown in Table-1. The optimum results acquired and the evolution of membership value were indicated in Table-2. According to experimental observation, the rate of dansylation increased rapidly with the rising temperature thus shorten the time taken for the reaction to get to equilibrium, but high $\mathrm{pH}$ maybe leads to a part of new derivative decomposition and hydrolysis of danysl chloride maybe accelerated by high temperature due to the dansylation react with the water in mixture. The experiment was consist with the previously reported $^{13}$, the rate of hydrolysis of danysl chloride is constant and low up to $\mathrm{pH} 9.5$ and above this $\mathrm{pH}$ it increased rapidly. Hence, dansylation reaction conditions must be obtained that minimize the side reaction. According to the experimental complex reaction and the strong polarity characteristics of dicyandiamide. Finally, a danysl chloride concentration ratio at least 10000 -fold great than dicyandiamide, a derivatization time of $10 \mathrm{~min}$, a derivatization temperature of $40{ }^{\circ} \mathrm{C}$ and a buffer $\mathrm{pH}$ of 9.5 were suggested as the dansylation condition.

\begin{tabular}{ccccc}
\multicolumn{5}{c}{ TABLE-1 } \\
& FACTORS AND LEVELS & \\
\hline & Ratio of & Reaction & Buffer/pH & Temperature \\
& DNS/DCD (A) & time/min $(\mathrm{B})$ & $(\mathrm{C})$ & $\left({ }^{\circ} \mathrm{C}\right)(\mathrm{D})$ \\
\hline 1 & 100000 fold & 10 & 9.5 & 40 \\
2 & 10000 fold & 30 & 10.8 & 60 \\
3 & 1000 fold & 60 & 11.8 & 20 \\
\hline
\end{tabular}

Stabilization of dansyl chloride and derivative: The sensitivity of dansyl chloride toward daylight is known, accordingly the paper report ${ }^{22}$ on the influence of light and 


\begin{tabular}{|c|c|c|c|c|c|}
\hline \multicolumn{6}{|c|}{$\begin{array}{c}\text { TABLE-2 } \\
\text { ORTHOGONAL LAYOUT }\end{array}$} \\
\hline NO. & A & B & $\mathrm{C}$ & $\mathrm{D}$ & Evaluating Indicator $(245 \mathrm{~nm} / \mathrm{A})$ \\
\hline 1 & $1(100000)$ & $1(10)$ & $1(9.5)$ & $1(40)$ & 0.179 \\
\hline 2 & 1 & $2(30)$ & $2(10.8)$ & $2(60)$ & 0.084 \\
\hline 3 & 1 & $3(60)$ & $3(11.8)$ & $3(20)$ & 0.056 \\
\hline 4 & $2(10000)$ & 1 & 2 & 3 & 0.056 \\
\hline 5 & 2 & 2 & 3 & 1 & 0.167 \\
\hline 6 & 2 & 3 & 1 & 2 & 0.105 \\
\hline 7 & $3(1000)$ & 1 & 3 & 2 & 0.060 \\
\hline 8 & 3 & 2 & 1 & 3 & 0.061 \\
\hline \multirow[t]{4}{*}{9} & 3 & 3 & 2 & 1 & 0.060 \\
\hline & $\mathrm{K}_{\mathrm{A} 1}=0.319$ & $\mathrm{~K}_{\mathrm{B} 1}=0.295$ & $\mathrm{~K}_{\mathrm{C} 1}=0.345$ & $\mathrm{~K}_{\mathrm{D} 1}=0.406$ & \\
\hline & $\mathrm{K}_{\mathrm{A} 2}=0.328$ & $\mathrm{~K}_{\mathrm{B} 2}=0.268$ & $\mathrm{~K}_{\mathrm{C} 2}=0.200$ & $\mathrm{~K}_{\mathrm{D} 2}=0.249$ & \\
\hline & $\mathrm{K}_{\mathrm{A} 3}=0.181$ & $\mathrm{~K}_{\mathrm{B} 3}=0.221$ & $\mathrm{~K}_{\mathrm{C} 3}=0.283$ & $\mathrm{~K}_{\mathrm{D} 3}=0.173$ & \\
\hline $\mathrm{R}$ & 0.147 & 0.074 & 0.145 & 0.233 & \\
\hline
\end{tabular}

TABLE-3

RESULTS OF WATER SAMPLES AND RECOVERY EXPERIMENT

\begin{tabular}{cccccc}
\hline Sample & $\begin{array}{c}\text { Amount of unspiked sample } \\
(\mathrm{ng} / \mathrm{L})\end{array}$ & $\begin{array}{c}\text { Amount of spiked } \\
(\mathrm{ng} / \mathrm{L})\end{array}$ & $\begin{array}{c}\text { Amount of spiked sample } \\
(\mathrm{ng} / \mathrm{L})\end{array}$ & $\begin{array}{c}\text { Recovery } \\
(\%)\end{array}$ & $\begin{array}{c}\text { Relative standard } \\
\text { deviations }(\%)\end{array}$ \\
\hline \multirow{3}{*}{ Water from stream } & 0 & 100 & 117 & 117 & \\
& 0 & 100 & 106 & 106 & 6.4 \\
\hline \multirow{2}{*}{ Simulated samples } & 0 & 100 & 120 & 51 & 93 \\
of tap water & 0 & 50 & 45 & 90 & 6.8 \\
\hline
\end{tabular}

storage stabilization of derivatization reagent and derivative. The experimental observations illustrated no significant change in content of the new derivative after extracted in glass bottles and exposed to daylight for $3 \mathrm{~h}$ at room temperature. In addition, dansyl chloride solution and new derivative can be stably preservated for one mouth at $0{ }^{\circ} \mathrm{C}$ of refrigerator.

Detection limits, recovery and sample results: The experiment selected two different type simulated water sample of tap water sample and stream water samples, Take some of dicyandiamide-spiked water samples were analyzed above described method. Concentration in the spiked samples were caculated through the standard comparison method. The recoveries and precision were calculated and shown in Table- 3 . Experiment relative standard deviations were less than $6.8 \%$, recoveries ranged from $90-120 \%$. Greater than $100 \%$ recovery maybe the result of interfering material such as urea, amino acide et $\mathrm{al}$. in stream water samples particularly. According to the stipulate of EPA-SW846 and standard deviation (repeat 20 times) of blank sample to estimate instrumental detection limit, Herein, successfully achieved method LOD $10 \mathrm{ng} / \mathrm{L}$ and LOQ $30 \mathrm{ng} / \mathrm{L}$ in clean water sample. The method is considered to be both accurate, because the recoveries are close to the known spiked values and precise because of the relatively low relative standard deviations of three replicate analysis.

\section{Conclusion}

In this work, the dansylation condition were optimized to ensure fast and sensitive determination trace dicyandiamide only by simple UV spectrometers. Moreover, the method was applied to analyze spike water samples. In this sense, the results obtained with this optimized method could be used to monitor the clean environment water samples.

\section{ACKNOWLEDGEMENTS}

The authors acknowledge the Department of Chemistry at Mississippi State University for financial support for this project.

\section{REFERENCES}

1. K.L. McGeough, R.J. Laughlin, C.J. Watson, C. Muller, M. Ernfors, E. Cahalan and K.G. Richards, Biogeosciences, 9, 4909 (2012).

2. H.J. Di and K.C. Cameron, J. Soils Sediments, 11, 1032 (2011).

3. L.L. Zhang, Z.J. Wu, L.J. Chen, H.J. Zhang, Y.L. Zhang and Z.H. Chen, Ecology and Environ. Sciences, 18, 1508 (2009).

4. K. Joji, T. Watanabe and T. Noboru, J. Chem. Soc. Jpn. Chem. Ind. Chem., 1, 37 (1997).

5. G.N. Lucas, Sri Lanka J. Child. Health, 42, 63 (2013).

6. L. Schep, W. Temple and M. Beasley, Clin. Toxicol., 47, 58 (2009).

7. J.E. Milks and R.H. Janes, Anal. Chem., 28, 846 (1956).

8. C.M. Zhou, J.P. Zhou, J. Wu and X.J. Li, Jiangsu J. Prev. Med., 20, 63 (2009).

9. L. Wu, B.J. Shi and Y. Wang, Chinese J. Biochem. Pharm., 30, 110 (2009).

10. C. Schwarzer and K. Haselwandter, J. Chromatogr. A, 732, 390 (1996).

11. J.B. Nair, J. Chromatogr. A, 671, 367 (1994).

12. S. Macmahon, T.H. Begley, G.W. Diachenko and S.A. Stromgren, J. Chromatogr. A, 1220, 101 (2012).

13. M. Turowski and B. Deshmukh, Anal. Lett., 37, 1981 (2004).

14. Z.X. Wang, J. Jiang, L. Sun, H.B. Zhou and Y.X. Zhao, J. Instrum. Anal., 31, 593 (2012).

15. J.J. Xu, J.X. Zhang, B.F. Huang and Y.P. Ren, J. Food Safety and Quality, 4, 415 (2013).

16. L. Wu, B.J. Shi and Y. Wang, Chin. Pharm. J., 10, 780 (2010).

17. S. Hiradate, T. Kamo, E. Nakajima, K. Kato and Y. Fujii, J. Chromatogr. A, 1098, 138 (2005).

18. X.Z. Chen, W.Q. Chen, J. Wang, L.Y. Huang and D.L. Zhang, Chinese J. Chromatogr., 31, 875 (2013).

19. Y. Tapuhi, D.E. Schmidt, W. Lindner and B.L. Karger, Anal. Biochem., 115, 123 (1981). 
20. H.L. Cai, R.H. Zhu, H.D. Li, J. Zhang and L.F. Li, J. Chromatogr. B, 879, 1993 (2011).

21. X.M. Cai, H. Zhao, M. Wu, X.Q. Hu, H.M. He, C.P. Zhang, C.R. Zhang and Z. Li, Chromatographia, 75, 1069 (2012).

22. W.F. Dong, X.Z. Li and W.X. Lin, J. Dalian Institute of Light Ind., 2, 115 (2005).

23. S. Chen, A.P. Ocampo and P.J. Kucera, J. Chromatogr. A, 558, 141 (1991).

24. A. Negro, S. Garbisa, L. Gotte and M. Spina, Anal. Biochem., 160, 39 (1987).

25. R. Bartzatt, Anal. Chim. Acta, 488, 203 (2003).
26. R. Nirogi, P. Komarneni, V. Kandikere, R. Boggavarapu, G. Bhyrapuneni, V. Benade and S. Gorentla, J. Chromatogr. B, 913-914, 41 (2013).

27. H.X. Wang, Y. Zhou and Q.W. Jiang, Food Addit. Contam. Part A, 30, 166 (2013).

28. T.Y. Kim and H.J. Kim, J. Chromatogr. A, 933, 99 (2001).

29. H. Yamada, A. Yamahara, S. Yasuda, M. Abe, K. Oguri, S. Fukushima and S. Ikeda-Wada, J. Anal. Toxicol., 26, 17 (2002).

30. M.E. AbdEl-Ghaffar, D.R. El-Wasseef, D.T. El-Sherbiny and S.M. ElAshry, J. Anal. Chem., 66, 476 (2011). 